\title{
VITTORIO HOLTIER
}

Absolvent al Institutului de Arte plastice şi decorative "Nicolae Grigorescu" Bucureşti secția de scenografie promoția 1970. Lucrarea de diplomă: Cartofi prajiți cu orice de Arnold Wesker, scenografie realizată la studioul Institutului de Arta Teatrală si Cinematografică Cassandra, spectacol regizat de Alexa Visarion.

După absolvire lucrează ca asistent scenograf în echipă cu Radu Boruzescu pentru un proiect Caragiale, film gândit de regizorul D. Esrig, apoi face asistență scenografilor Radu Boruzescu şi Helmut Sturmer, realizatori ai decorurilor unor filme de o deosebită calitate: Duhul Aurului şi Nunta de piatră în regia lui Mircea Veroiu şi Dan Pița.

Intre 1970 - 2007 realizează în teatre din țară şi Bucureşti, scenografia a peste 50 de lucrări de teatru - decoruri şi costume, precum şi decorurile a patru filme artistice de lung metraj (Zidul - 1974, regia C. Vaeni, Mere roşii - 1976 regia Alexandru Tatos, Inainte de tăcere 1978, regia Alexa Visarion şi Lişca - 1983, regia Ion Cărmăzan).

Lucrează cu regizori importanți ai generației sale: Alexa Visarion, Aureliu Manea, Alexandru Tatos, Dragoş Galgoțiu, Alexandru Dabija, Cristian - Hadji Culea, Eugenia lonescu.

Membru al UAP din 1977 şi membru UNITER din 1990.

Din 2005 lucrează ca profesor asociat în cadrul catedrei de scenografie a U.N.A., asistent, lector doctorand şi conferențiar, în 2008 îşi susține teza de doctorat

"Pseudoskenographikos sau fals tratat de înscenosofare", având conducător de lucrare pe prof. univ. dr. Alexa Visarion.

Predă arta compoziției scenografice, a condus lucrări de licență şi studii masterale. In prezent lucrează cu o grupă de studenți ai anului 2 şi conduce studiul de masterat pentru studenți ai anului 1 master.

\section{Decoruri şi costume pentru spectacole de teatru (selectiv)}

Meşterul Manole de Lucian Blaga, regia Alexa Visarion, Teatrul Național Cluj (1973)

Năpasta de I.L. Caragiale, regia Alexa Visarion, Teatrul Giuleşti, Bucureşti (1974)

Barbarii de M. Gorki, regia Alexa Visarion, Teatrul Nottara (1976)

Lapte de pasăre (Timpul în doi) de D.R. Popescu, regia Alexandru Tatos, Teatrul de Stat Ploieşti (1977)

Arden din Kent, anonim elisabethan, regia Aureliu Manea, Teatrul de Stat Ploieşti (1978)

Casa Bernardei Alba de Federigo Garcia Lorca, regia Eugenia Ionescu, Teatrul C.I. Nottara (1980)

A treia țeapă de Marin Sorescu, regia Letiția Popa, Teatrul de Stat Ploieşti (1979)

D’ale carnavalului de I.L. Caragiale, regia Dragoş Galgoțiu, Teatrul de Stat Ploieşti (1984)

Conu Leonida față cu reacțiunea de I.L. Caragiale, regia Dragoş Galgoțiu, Teatrul Municipal Ploieşti (1986)

Mult zgomot pentru nimic de W. Shakespeare, regia Dragoş Galgoțiu, Teatrul de Stat Ploieşti (1988)

Trei surori de A.P. Cehov, regia Aureliu Manea, Teatrul Municipal “Toma Caragiu”, Ploieşti (1989)

Tragica istorie a doctorului Faustus de C.Marlowe, regia Dragoş Galgoțiu, Teatrul Odeon (1991) 
Teatru seminar de Petre Țuțea, regia Dragoş Galgoțiu, Teatrul Odeon (1992) Sganarelle de Moliere, regia Dragoş Galgoțiu, Teatrul Odeon (1997)

Lulu de F. Wedekind, regia Dragoş Galgoțiu, Teatrul Odeon (1995)

Troilus şi Cresida de W. Shakespeare, regia Dragoş Galgoțiu, Teatrul de Comedie (1995)

Copiii soarelui de M. Gorki, regia Cristian Hadji-Culea, Teatrul Mic (1997)

Upercut stânga de Joel Jouaneau, regia Dragoş Galgoțiu, Teatrul Odeon (1997)

Furtuna de W. Shakespeare, regia Dragoş Galgoțiu, Teatrul Maghiar Cluj (1998)

Regele Lear de W. Shakespeare, regia Dragoş Galgoțiu, Teatrul Bulandra, Bucureşti (1999)

M. Butterfly de Henri D. Hwang, regia Ada Maria Lupu, Teatrul Odeon (1999)

Cafeneaua de Goldoni, regia Dragoş Galgoțiu, Teatrul Odeon (2000)

Gaitele de Al. Kiritescu, regia Alexandru Dabija, Teatrul Odeon (2002)

Arden din Feversham, anonim elisabethan, regia Dragoş Galgoțiu, Teatrul Odeon (2003)

joi.megaJoy de Katalin Thuroczy, regia Radu Afrim, Teatrul Odeon (2006)

Ultima femeie a Senorului Juan de Leonid Juhovitki, regia Vladimir Granov (2007)

\section{Expoziții}

Participă de la absolvire la toate Trienalele de scenografie din România, la Quadrienalele de scenografie de la Praga, la expozițiile de scenografie românească în RDG, la expozițiile internaționale de scenografie de la Novisad.

Expoziție personală de grafică la galeria Galateea Bucureşti (1978)

Expoziție personală de pictură la galeria Galateea Bucureşti (1982)

Expoziție personală de pictură la Căminul Artei Bucureşti (2001)

Expoziție de pictură la Galeria Căminul Artei "Noaptea: principiu şi taină” împreună

cu teoreticianul George Banu (2004)

Expoziție de pictură, grafică şi scenografie "Turnul şi insula, încercare de abordare a universului shakespearean prin arhetipuri ale centralității”, în cadrul Festivalului Național de Teatru, Bucureşti, centrul cultural Kalinderu (2005). Aceeaşi expoziție este reluată pe alte coordonate în cadrul Festivalului W. Shakespeare, Craiova (2006)

\section{Premii}

Premiul ATM pentru scenografie pentru spectacolul Timpul în doi (1976)

Premiul I pentru scenografie de film Mere roşii (1976)

Premiul I pentru scenografie de teatru pentru spectacolul $A$ treia țeapă (1977)

Premiul I la concursul de pictură Rovigo Italia şi medalia de argint la concursul pictură Italia (1989)

Premiul UAP pentru scenografie (1991)

Nominalizat de UNITER pentru scenografia spectacolelor Troilus şi Cresida de W. Shakespeare (Teatrul de Comedie) şi Lulu de F. Wedekind (Teatrul Odeon) (1995)

Premiul UNITER pentru întreaga activitate (2002)

Nominalizat de UNITER pentru scenografia spectacolului Arden din Feversham

(Teatrul Odeon) (2003) 


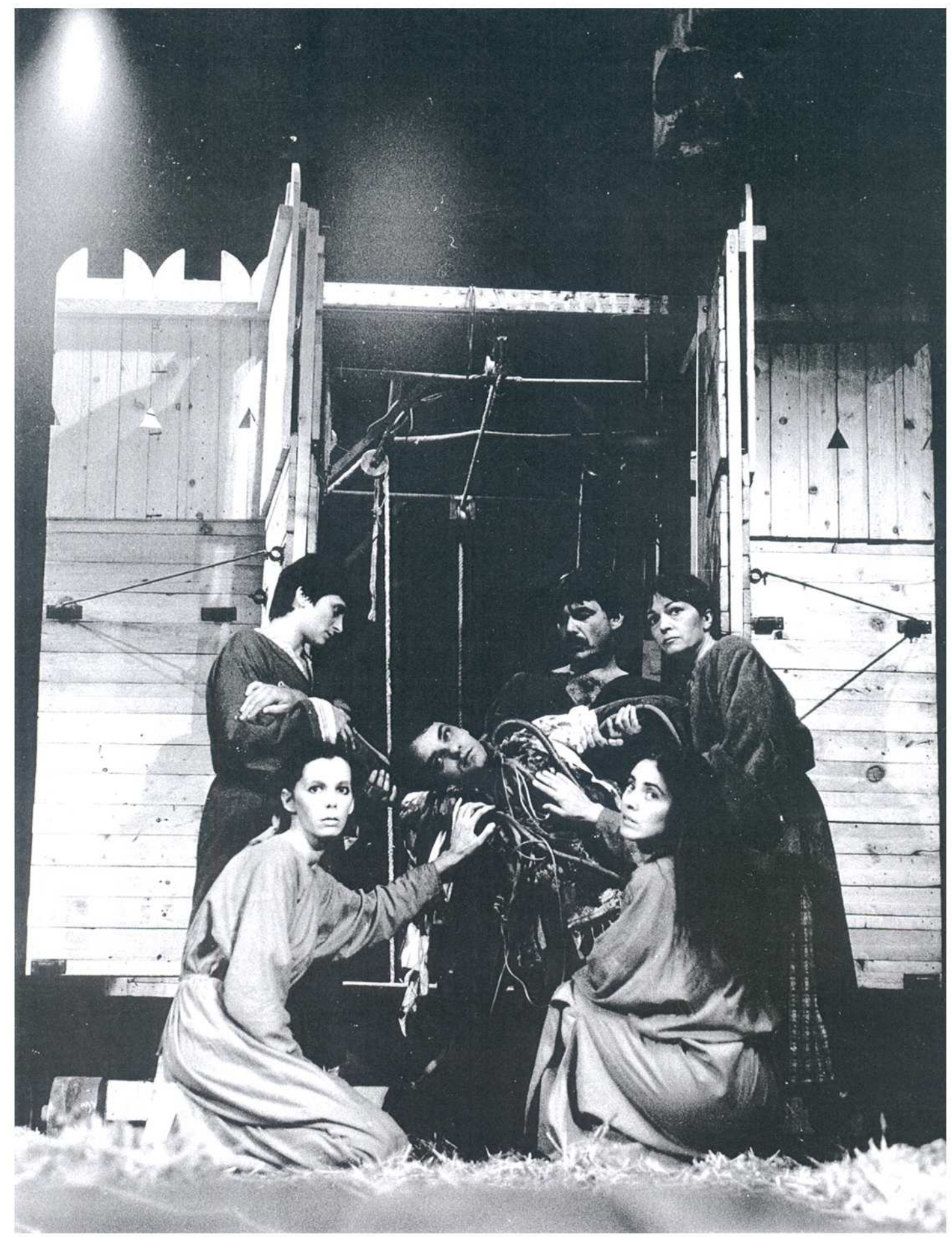

Elemente decor şi recuzită pentru spectacolul Mult zgomot pentru nimic de W. Shakespeare, regia Dragoş Galgoțiu, Teatrul de Stat Ploieşti 1988 


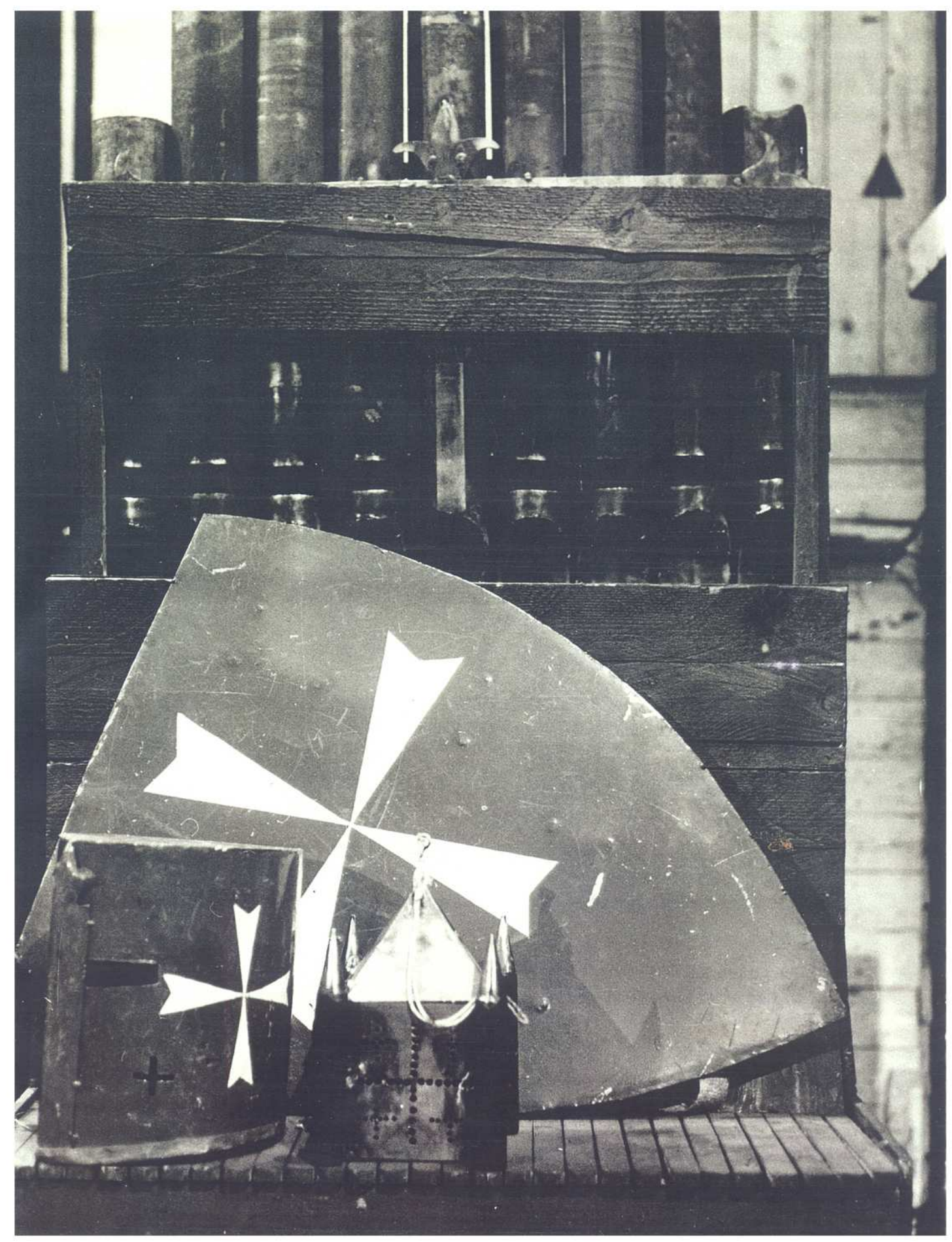

Elemente decor şi recuzită pentru spectacolul Mult zgomot pentru nimic de W. Shakespeare, regia Dragoş Galgoțiu, Teatrul de Stat Ploieşti 1988 


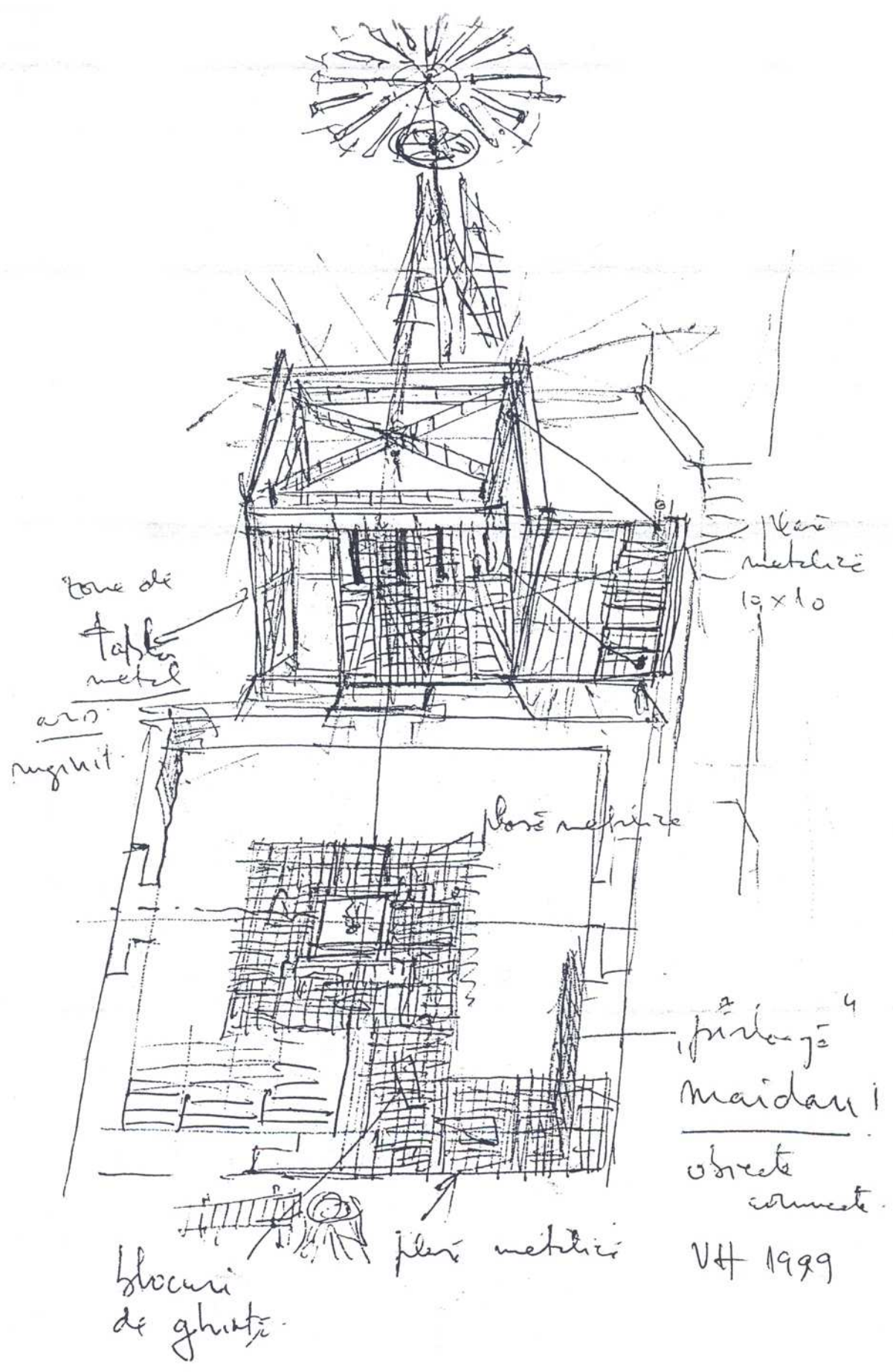

Schiță dispozitiv scenografic pentru spectacolul Regele Lear de W. Shakespeare regia Dragoş Galgoțiu, Teatrul Bulandra 1999 


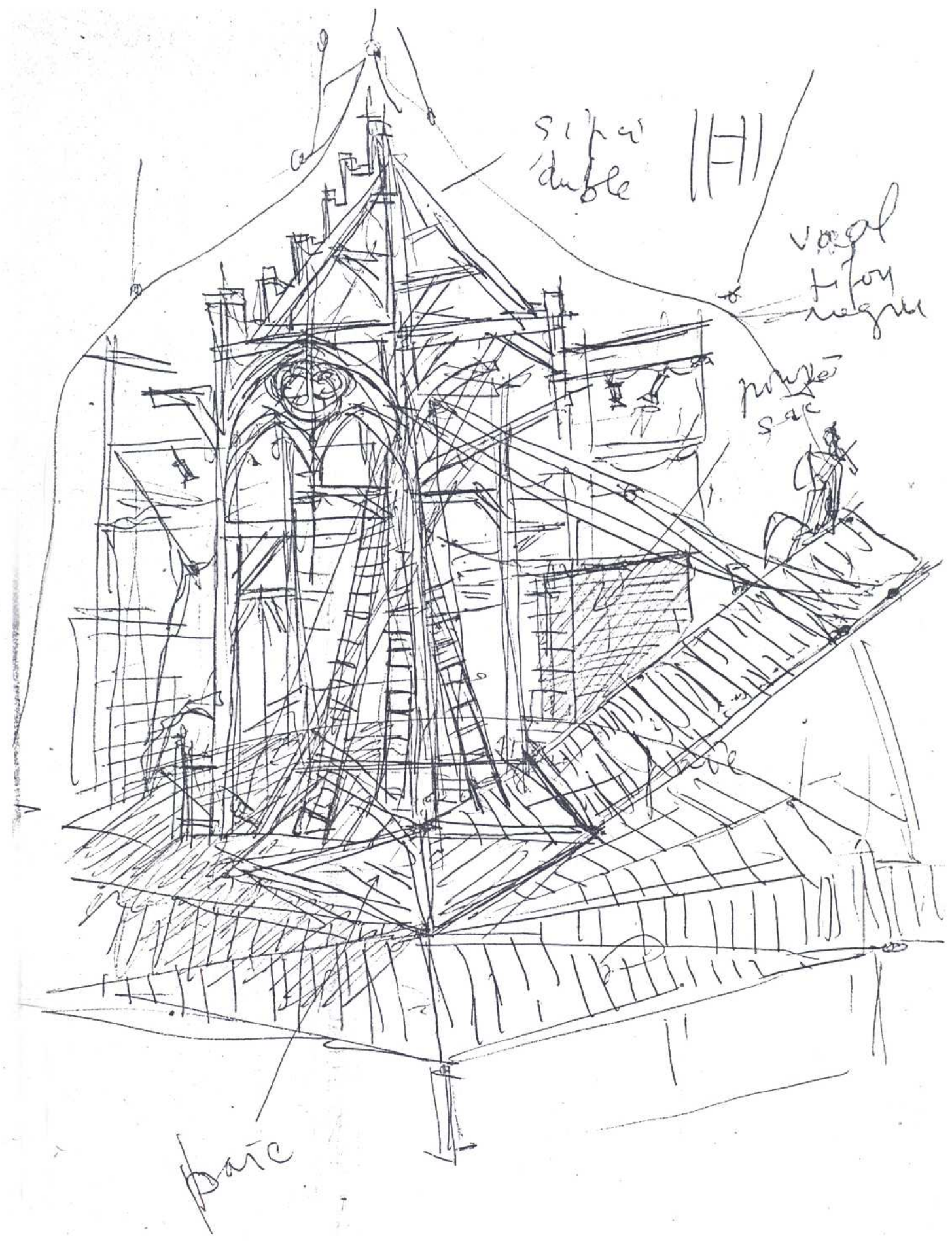

Studiu pentru spectacolul Arden din Feversham, anonim elisabethan, regia Dragoş Galgoțiu, Teatrul Odeon 2003 


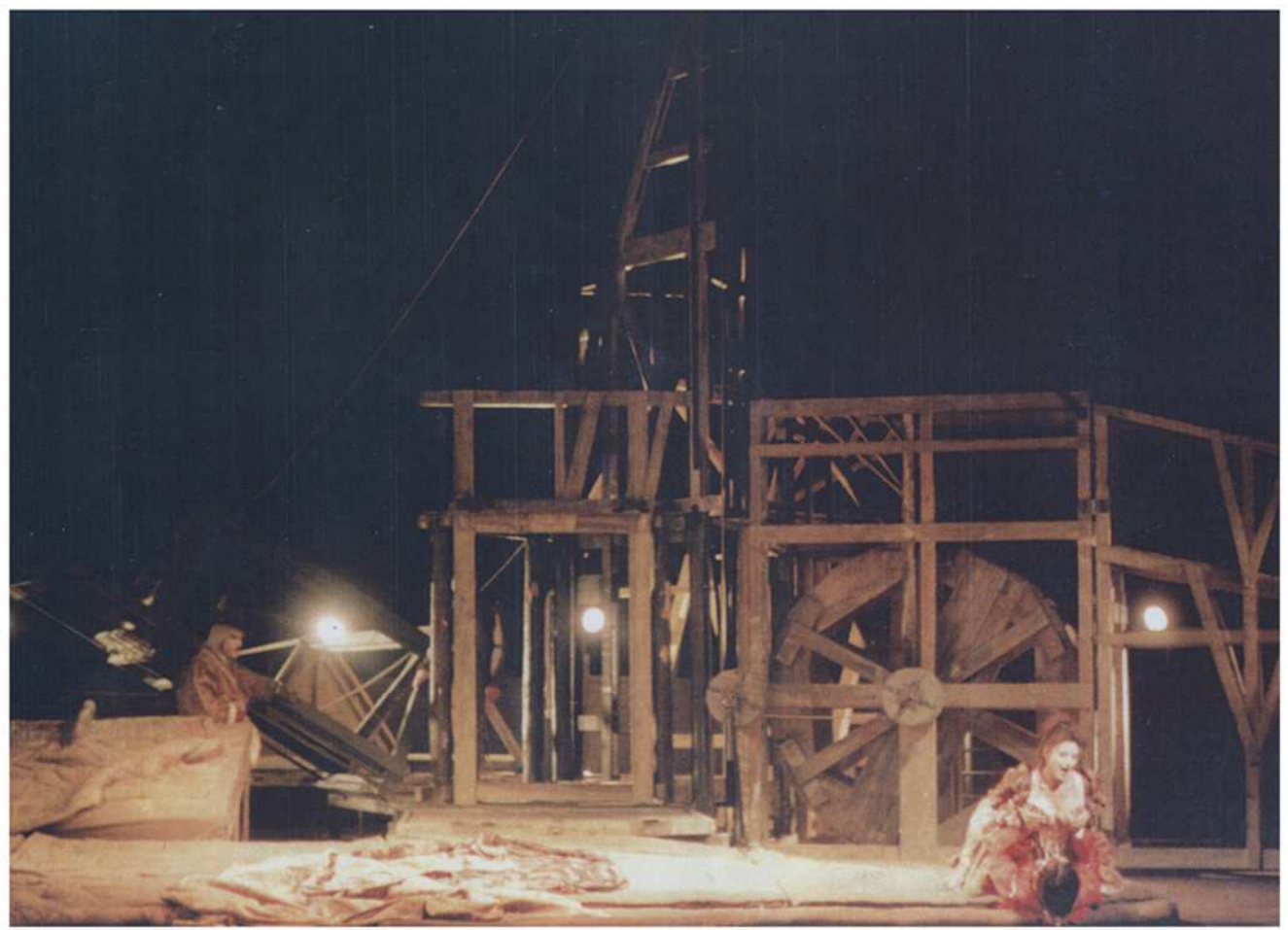

Elemente din spectacolul Arden din Feversham, anonim elizabethan, regia Dragoş Galgoțiu, Teatrul Odeon 2003

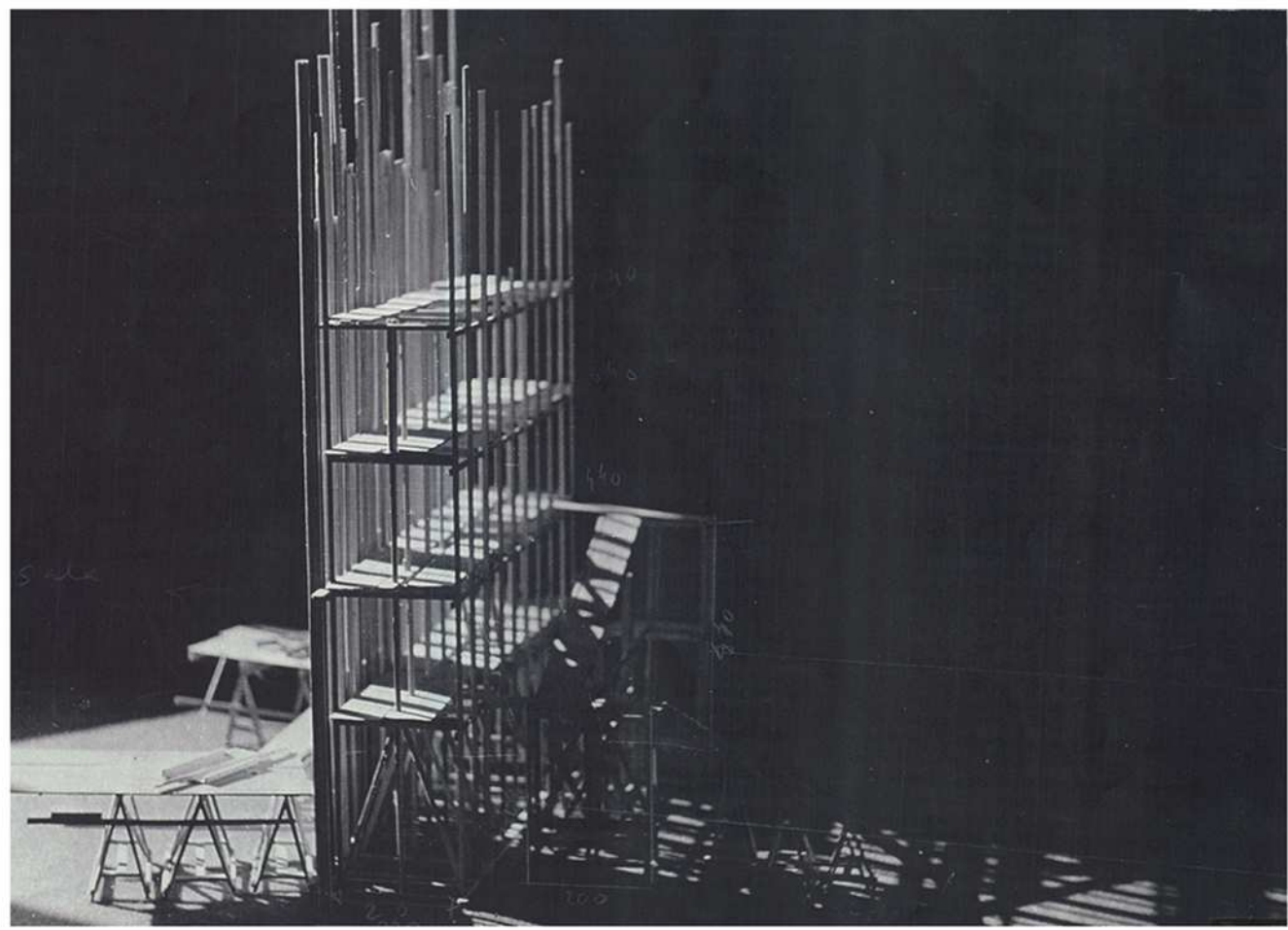

Machetă decor pentru spectacolul Meşterul Manole de Lucian Blaga, regia Alexa Visarion, Teatrul Național Cluj 1973 